\title{
Localization and Functional Studies of Pendrin in the Mouse Inner Ear Provide Insight About the Etiology of Deafness in Pendred Syndrome
}

\author{
Ines E. Royaux, ${ }^{1}$ Inna A. Belyantseva, ${ }^{2}$ Tao Wu, ${ }^{3}$ Bechara Kachar, ${ }^{2}$ Lorraine A. Everett, ${ }^{1}$ \\ Daniel C. Marcus, ${ }^{3}$ and Eric D. Green ${ }^{1}$ \\ ${ }^{1}$ Genome Technology Branch, National Human Genome Research Institute, National Institutes of Health, Bethesda, MD \\ 20892, USA \\ ${ }^{2}$ Laboratory of Cellular Biology, National Institute on Deafness and Other Communication Disorders, National Institutes of \\ Health, Bethesda, MD 20892, USA \\ ${ }^{3}$ Department of Anatomy and Physiology, Kansas State University, Manhattan, KS 66506, USA
}

Received: 4 October 2002; Accepted: 12 February 2003; Online publication: 14 April 2003

\begin{abstract}
Immunolocalization studies of mouse cochlea and vestibular end-organ were performed to study the expression pattern of pendrin, the protein encoded by the Pendred syndrome gene $(P D S)$, in the inner ear. The protein was restricted to the areas composed of specialized epithelial cells thought to play a key role in regulating the composition and resorption of endolymph. In the cochlea, pendrin was abundant in the apical membrane of cells in the spiral prominence and outer sulcus cells (along with their root processes). In the vestibular end-organ, pendrin was found in the transitional cells of the cristae ampullaris, utriculi, and sacculi as well as in the apical membrane of cells in the endolymphatic sac. $P d s$ knockout $\left(P d s^{-/}\right)$mice were found to lack pendrin immunoreactivity in all of these locations. Histological studies revealed that the stria vascularis in $P d s^{-1-}$ mice was only two-thirds the thickness seen in wildtype mice, with the strial marginal cells showing irregular shapes and sizes. Functional studies were also performed to examine the role of pendrin in endolymph homeostasis. Using double-barreled electrodes placed in both the cochlea and the utricle, the endocochlear potential and endolymph potassium
\end{abstract}

Correspondence to: Eric D. Green - National Human Genome Research Institute 50 South Dr. $\cdot$ Bldg. $50 \cdot$ Rm. $5523 \cdot$ Bethesda, MD 20892. Telephone: (301) 402-0201; fax: (301) 402-4735; email: egreen@nhgri.nih.gov concentration were measured in wild-type and $\mathrm{Pds}-1-$ mice. Consistent with the altered strial morphology, the endocochlear potential in $P d s^{-/-}$mice was near zero and did not change during anoxia. On the other hand, the endolymphatic potassium concentration in $P d s^{-/-}$mice was near normal in the cochlea and utricle. Together, these results suggest that pendrin serves a key role in the functioning of the basal and/ or intermediate cells of the stria vascularis to maintain the endocochlear potential, but not in the potassium secretory function of the marginal cells.

Keywords: pendred syndrome, pendrin, anion transporter, cochlea, knockout mouse, endocochlear potential

\section{INTRODUCTION}

Pendred syndrome is an autosomal recessive disorder characterized by deafness and goiter (OMIM 274600, see www.ncbi.nlm.nih.gov:80/entrez/query.fcgi?db= OMIM). The goiter is variable in severity, is caused by a defect in the incorporation of iodide into thyroglobulin, and is associated with an abnormal perchlorate discharge test (Fraser et al. 1960; Reardon and Trembath 1996). The deafness in Pendred syndrome is sensorineural in nature with variable time of onset. Affected individuals often have structural malforma- 
tions of the inner ear, ranging from isolated dilatation of the vestibular aqueduct to a Mondini malformation, where the cochlea is missing its apical turn and has an underdeveloped modiolus (Johnsen et al. 1986; Phelps et al. 1998). Some patients with Pendred syndrome show evidence of vestibular dysfunction (episodic vertigo, tinnitus, and vomiting), similar to that seen in Meniere's disease (Das 1987; Stinckens et al. 2001).

The gene (PDS; also called SLC26A4) mutated in Pendred syndrome was identified in 1997 (Everett et al. 1997). Immunolocalization studies demonstrated that the encoded protein, pendrin, is present in the apical membrane of thyrocytes, where it most likely acts as an iodide transporter (Bidart et al. 2000b; Royaux et al. 2000). Pendrin has also been found in the bicarbonate-secreting cells of the cortical collecting ducts of the kidney (Royaux et al. 2001), the secretory epithelium of the uterus (Suzuki et al. 2002), syncytiotrophoblasts (Bidart et al. 2000a), Sertoli cells (Lacroix et al. 2001), and the mammary gland (Rillema and Hill 2003).

Elucidating the cellular expression pattern and function of pendrin in the inner ear is particularly important since it might provide insight about the etiology of hearing loss in Pendred syndrome. Previous studies involving mRNA in situ hybridization of mouse inner-ear tissue demonstrated that $P d s$ is expressed in the endolymphatic duct and sac, in discrete areas adjacent to the maculae of the utricle and saccule, and in the spiral prominence region within the scala media of the cochlea (Everett et al. 1999). Here, we have extended these studies by establishing the locations of the pendrin protein in various substructures of the mouse inner ear. In addition, we have used a $P d s$-knockout mouse model (Everett et al. 2001) to examine the role of pendrin in endolymph homeostasis.

\section{METHODS}

\section{Pds-knockout mice}

Wild-type $\left(P d s^{+/+}\right)$and $P d s$-knockout $\left(P d s^{-/-}\right)$mice were obtained from matings of $P d s^{+/-}$mice. The generation and phenotypic characterization of the $P d s^{-/-}$mice have been described (Everett et al. 2001).

\section{Immunofluorescence studies}

Whole-mount immunohistochemical studies of mouse inner-ear specimens were performed essentially as described (Belyantseva et al. 2000). Specifically, 2-4-week-old mice were euthanized according to the NIH animal care and use procedure by $\mathrm{CO}_{2}$, and their temporal bones removed. Cochleae were dissected out of the temporal bone and perfused with $4 \%$ paraformaldehyde in phosphate-buffered saline (PBS; $137 \mathrm{mM} \mathrm{NaCl}, 2.7 \mathrm{mM} \mathrm{KCl}, 4.3 \mathrm{mM} \mathrm{Na}_{2} \mathrm{HPO}_{4}$. $7 \mathrm{H}_{2} \mathrm{O}, 1.4 \mathrm{mM} \mathrm{KH}_{2} \mathrm{PO}_{4}$ ) through the round and oval windows and a small fenestra in the apex of the cochlear bony capsule. The cochleae were then postfixed in the same solution for $2 \mathrm{~h}$ at room temperature and washed in PBS. Segments of stria vascularis and organ of Corti together with Reissner's membrane were dissected out using a fine needle. Samples were permeabilized in $0.5 \%$ Triton X-100 for $30 \mathrm{~min}$ and washed with PBS, followed by overnight incubation at $4^{\circ} \mathrm{C}$ in blocking solution (2\% bovine serum albumin, $5 \%$ normal goat serum; Vector Laboratories, Burlingame, CA). The tissue was then incubated for $1 \mathrm{~h}$ at room temperature with affinitypurified pendrin antibody h760-780 (Royaux et al. 2001) diluted 1:1000 in blocking solution. After washing in PBS, specimens were incubated for 40 $\mathrm{min}$ in fluorescein-conjugated goat anti-rabbit secondary antibody (1:250 dilution; Vector Laboratories) and then stained with rhodamine-phalloidin (1:100 dilution; Molecular Probes, Eugene, OR). After washing in PBS, tissues were mounted using the ProLong Antifade kit (Molecular Probes) for $20 \mathrm{~min}$ at room temperature. Special attention was paid during mounting of the samples in order to make Reissner's membrane flat and nonwrinkled, without covering the organ of Corti. The images were obtained using a laser scanning confocal microscope (Zeiss LSM510).

To dissect out the endolymphatic sac (ES), 2-weekold C57Bl6 $(n=4)$ and Pds-knockout $(n=5)$ mice were euthanized as described above. The temporal bones were removed and fixed with $4 \%$ paraformaldehyde for $2 \mathrm{~h}$ at room temperature. The dura mater encephali of the posterior cerebral fossa containing the ES was removed from the temporal bone using a fine needle and microscissors using a dissection microscope. The entire ES was opened from the edge of the proximal sac portion and processed for immunocytochemistry in the same manner as pieces of the organ of Corti. The ES was mounted flat in a drop of antifade media with its luminal surface up on a glass slide, covered with a coverslip, and examined by scanning confocal microscopy.

\section{Endocochlear potential and endolymphatic potassium measurements}

$P d s^{-/-}$and appropriately matched wild-type (129Sv/ Ev) mice were studied at 4-7 weeks of age, when the auditory system is normally mature. Animals were anesthetized with inactin (thiobutabarbital sodium salt; Sigma Chemical, St. Louis, MO) at a dose of 140 
$\mathrm{mg} / \mathrm{kg}$ (IP), and anoxia was induced by intramuscular injection of succinylcholine chloride $(1 \mathrm{mg} / \mathrm{g})$ after establishment of deep anesthesia followed by occlusion of the trachea. The endocochlear potential (EP) and endolymphatic potassium concentration $\left(\left[\mathrm{K}^{+}\right]\right)$were measured with double-barreled microelectrodes as described previously (Marcus et al. 2002). Measurements were made in the apical turn of the cochlea after thinning the bone over the stria vascularis and creating a small hole $(\sim 30 \mu \mathrm{m})$ for probe entry or in the basal turn by an approach through the round window membrane. The utricular potential and $\left[\mathrm{K}^{+}\right]$were measured with techniques similar to those described above for the cochlea. The utricle was approached by removal of the stapes from the oval window. Potassium-selective electrodes were calibrated as in previous studies (Marcus et al. 2002). In conjunction with the EP and $\left[\mathrm{K}^{+}\right]$measurements, routine histological examination of the stria vascularis was performed. For these studies, mice were transcardially perfused with $2.5 \%$ glutaraldehyde, $1.5 \%$ paraformaldehyde in $150 \mathrm{mM}$ $\mathrm{NaCl}, 2 \mathrm{mM} \mathrm{KH}{ }_{2} \mathrm{PO}_{4}, 8 \mathrm{mM} \mathrm{Na} \mathrm{HPO}_{4}(\mathrm{pH}$ 7.3). Temporal bones were removed. The perilymphatic scalae were then perfused with the same fixative, and the ears postfixed for $24 \mathrm{~h}$ at $4^{\circ} \mathrm{C}$. Temporal bones were then decalcified in Cal-EX (Fisher Scientific, Boston, MA) for 2 days, dehydrated in graded alcohol and xylene, embedded in paraffin, sectioned at $5-\mu \mathrm{m}$ thickness, and stained with hematoxilin and eosin. The Institutional Animal Care and Use Committee of Kansas State University approved all experimental protocols.

\section{RESULTS}

\section{Localization of pendrin in the cochlea}

Immunofluorescence staining of mouse cochlea using an anti-pendrin antibody demonstrated the presence of the protein in outer sulcus cells and in the apical membrane of cells of the spiral prominence (Fig. 1a). The level of expression was variable from cell to cell. Pendrin immunoreactivity was absent in the stria vascularis, Reissner's membrane, and the organ of Corti. The outer sulcus cells reside between cells of the spiral prominence, neighboring the stria vascularis and the supporting cells of Claudius. They form a single cuboidal cell layer, as visualized by staining with rhodamine-phalloidin (OSC; Fig. 1a, left panel). The outer sulcus cells are associated with long projections (outer sulcus cell roots, SCR) that extend into the spiral ligament. Optical sections revealed cell processes throughout the plasma membrane that stain for pendrin in a nonpolarized pattern (Fig. 1b).

\section{Localization of pendrin in the vestibular system}

Immunofluorescence staining of mouse vestibular end-organ revealed the presence of pendrin in the transitional epithelium of the utricle and saccule, next to the sensory epithelium of the macula (Fig. 2a). The luminal membrane of these cells that faces the endolymphatic space was strongly labeled with the anti-pendrin antibody (see inset of Fig. 2a). As with the utricle and saccule, the pendrin-positive cells of the ampullae (Fig. 2b) are the transitional cells residing next to the sensory epithelium.

Localization of pendrin in the endolymphatic sac

Immunofluorescence staining of mouse endolymphatic sac allowed two cell types to be discerned. Pendrin was detected in the apical membrane of cells that protrude slightly into the lumen (Fig. 3a-d); these cells might correspond to the mitochondriarich cells (or light cells) described previously (Dahlmann and von During 1995; Furuta et al. 1991; Lundquist 1976). This membrane is populated with abundant microvilli that show significant immunoreactivity with the anti-pendrin antibody (data not shown). The pendrin-positive cells represent roughly one-third of the epithelial cells that label with rhodamine-phalloidin; it is interesting to note that previous reports indicated that the mitochondria-rich cells constitute $\sim 30 \%$ of the endolymphatic sac epithelial cells in mice (Hultcrantz et al. 1988). A similar proportion of pendrin-positive cells was also found in the distal portion of the endolymphatic sac (Figs. 3i and $\mathrm{j}$ ); these cells are flat, and their apical plasma membrane does not protrude into the lumen. The presence of morphologically distinct cells in the distal portion of the endolymphatic sac that seem to correspond to the bulging cells of the proximal portion is consistent with previous findings (Dahlmann and von During 1995).

\section{Examination of whole-mount inner-ear specimens from Pds-knockout mice}

Parallel studies were also performed using inner-ear specimens obtained from Pds-knockout mice (Everett et al. 2001). Immunofluorescence staining of the cochlea and vestibular end-organ from $\mathrm{Pds}{ }^{-/-}$mice failed to reveal any pendrin immunoreactivity; for example, no pendrin labeling was seen in the spiral prominence region (Fig. 4a, compare with Fig. 1a). Interestingly, in adult $P d s^{-/-}$mice, the marginal cells of the stria vascularis do not form the typical cobblestone pattern and show very irregular shapes and 
a

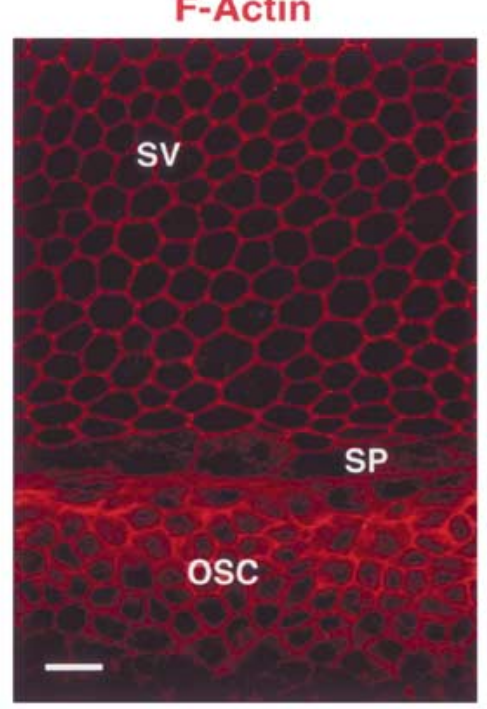

Merged

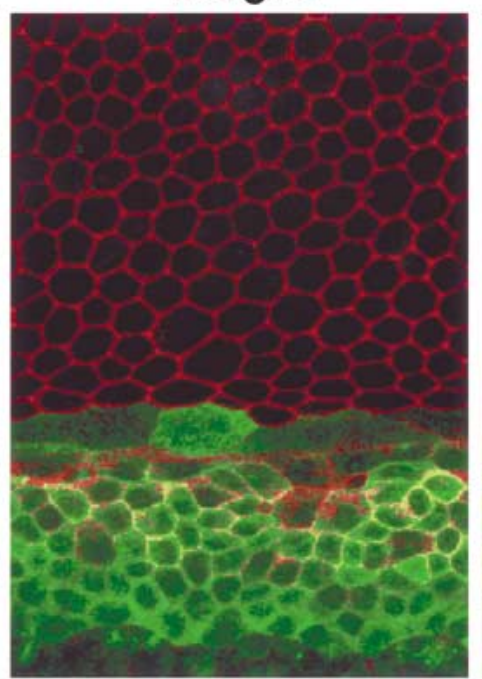

Pendrin

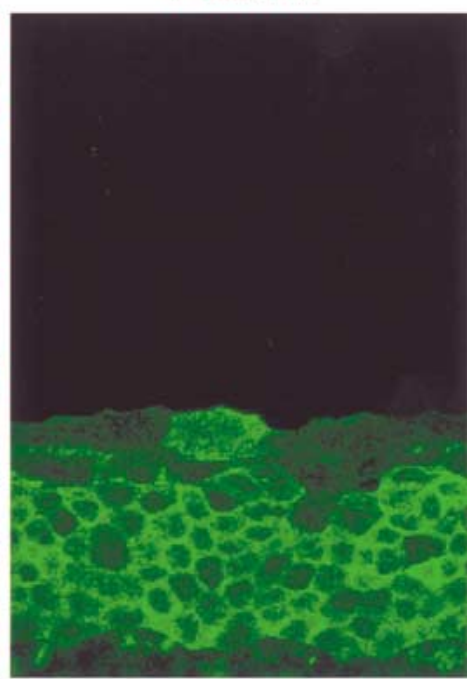

b
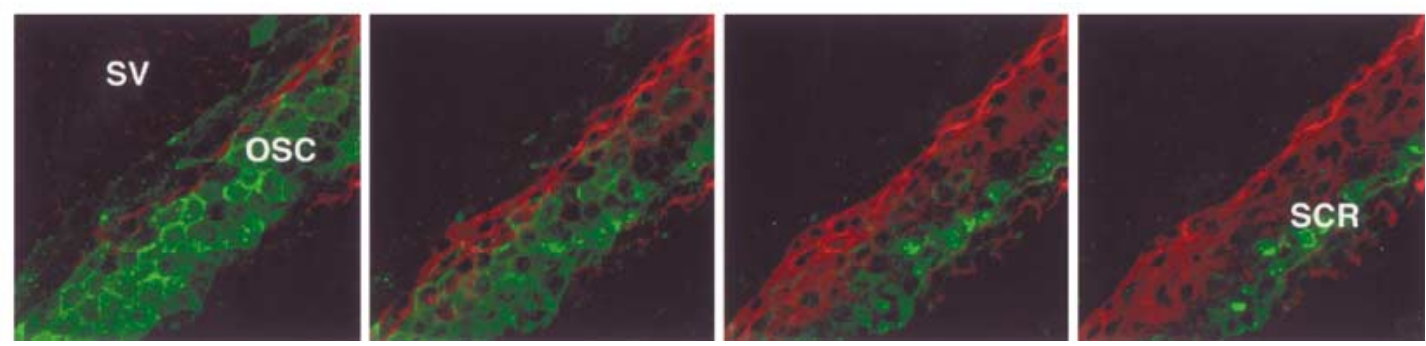

FIG. 1. Immunolocalization of pendrin in the mouse cochlea. Whole-mount cochlea preparations from a 2-week-old mouse were stained with an anti-pendrin antibody followed by FITC-conjugated anti-rabbit antiserum and rhodamine-phalloidin (F-actin staining). a. The labeling of F-actin (red) is shown on the left; note the contour of the epithelial cells (facing upward) and the various cell populations (SV: stria vascularis; SP: spiral prominence; OSC: outer sulcus cells). Also note the distinctive cobblestone arrangement of marginal cells of the stria vascularis. The labeling of pendrin (green) is shown on the right. The merged image, shown in the middle, reveals the two pendrin-staining populations of cells next to the stria vascularis; these include epithelial cells of the spiral prominence and outer sulcus cells. Note the heterogeneous levels of pendrin labeling from cell to cell. Scale bar $=20 \mu \mathrm{m}$. b. Optical sections of the abovelabeled cochlea reveal the presence of pendrin (green) in the sulcus cell roots (SCR) underneath the layer of outer sulcus cells.
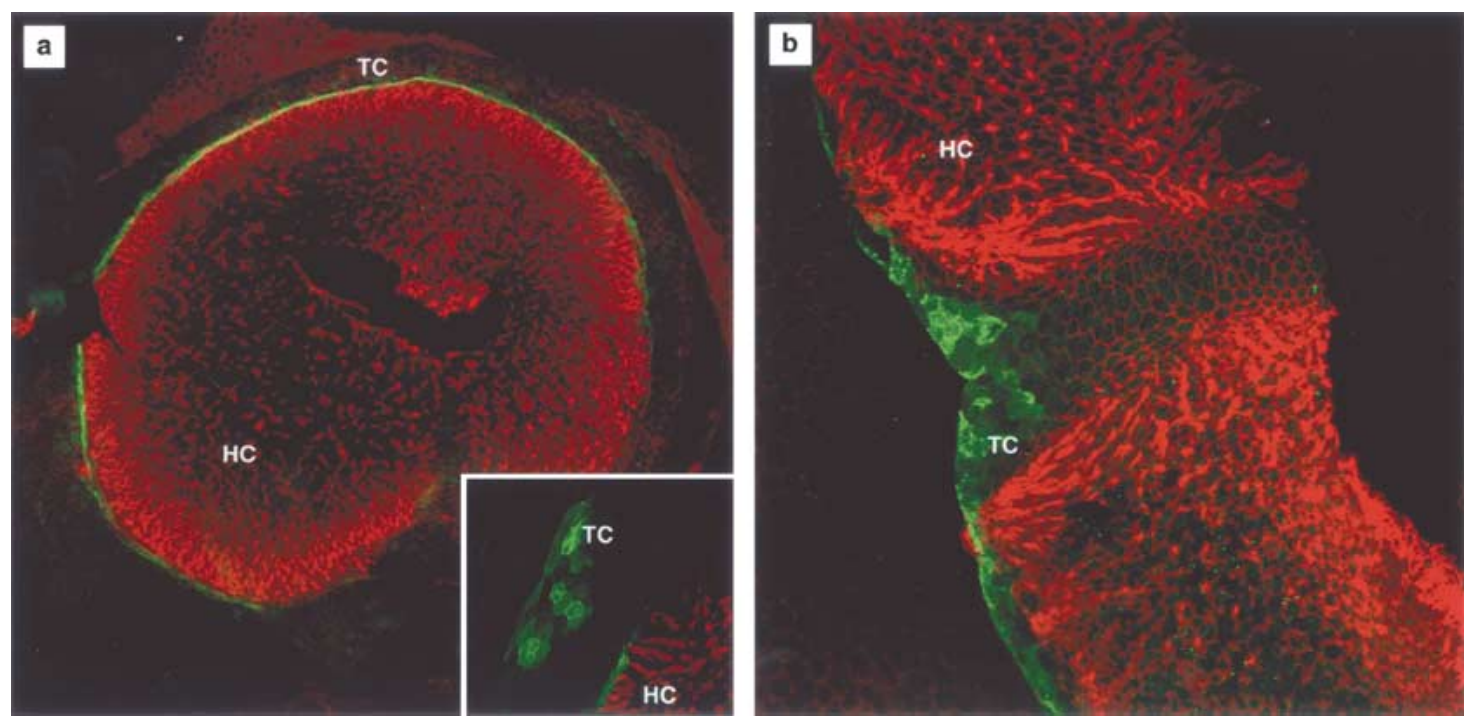

FIG. 2. Immunolocalization of pendrin in the mouse vestibular end-organ. Whole-mount preparations of macula utriculi from a 2week-old mouse were stained with an anti-pendrin antibody followed by FITC-conjugated anti-rabbit antiserum and rhodaminephalloidin (F-actin staining). a. The round plaque with actin-rich (red) hair cells (HC) corresponds to the macula of the utricle. Pendrin staining (green) is seen in the apical membrane of cells adjacent to the sensory epithelium and identified as vestibular transitional cells (TC). The latter is more clearly seen at higher magnification (in the inset). b. In the ampulla, pendrin labeling (green) is also seen in the apical membrane of vestibular transitional cells that neighbor the sensory epithelium. 

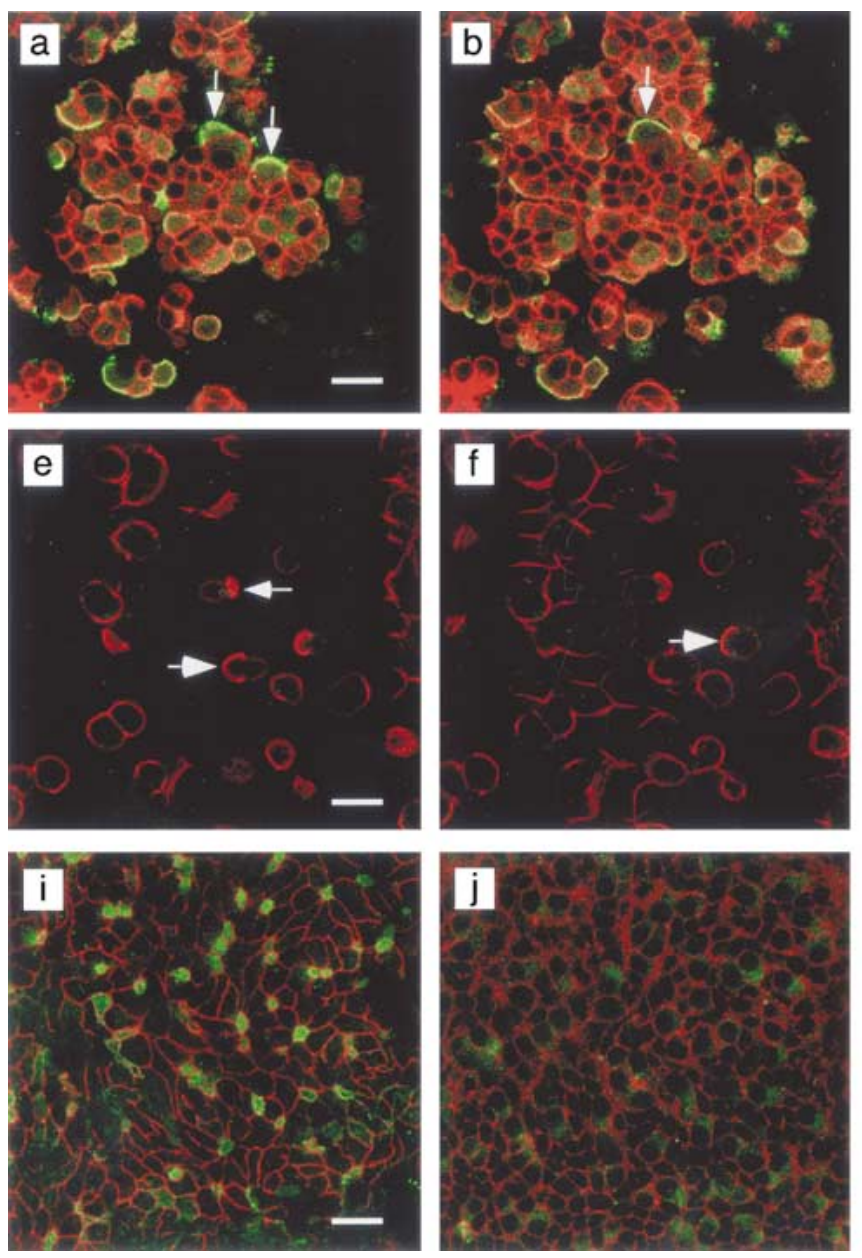

FIG. 3. Immunolocalization of pendrin in the endolymphatic sac of wild-type and $P d s$-knockout mice. Whole-mount preparations of the proximal and distal portions of the endolymphatic sac from 2-week-old mice were stained with an anti-pendrin antibody followed by FITCconjugated anti-rabbit antiserum and rhodamine-phalloidin. $\mathbf{a}-\mathbf{h}$. Optical sections through the epithelium of the proximal portion of the endolymphatic sac of wild-type (a-d) and Pds-knockout (e-h) mice. Panels a and e show the most superficial sections through the epithelium facing the endolymphatic space. Arrows indicate the apical surfaces of bulging cells that stain positive for pendrin (green)

sizes. This abnormality appears at roughly one month of age. Confocal imaging of the stria vascularis shows loss of the cobblestone pattern of marginal cells and signs of degeneration in the intermediate and basal cell layers (Fig. 4). The tight junctional barrier of the basal cell layer is compromised by the degeneration of some basal cells, which appears as abnormal openings in this cell layer (Fig. 4c). Pendrin immunoreactivity was also absent in the endolymphatic sac in $P d s^{-/-}$mice (Fig. 3e-h, k, and 1). Once again, the morphology of this inner-ear structure is abnormal in Pds-knockout mice, being notably dilated and relatively easy to remove by dissection. These findings are consistent with the increased volume of endolymphatic spaces (i.e.,
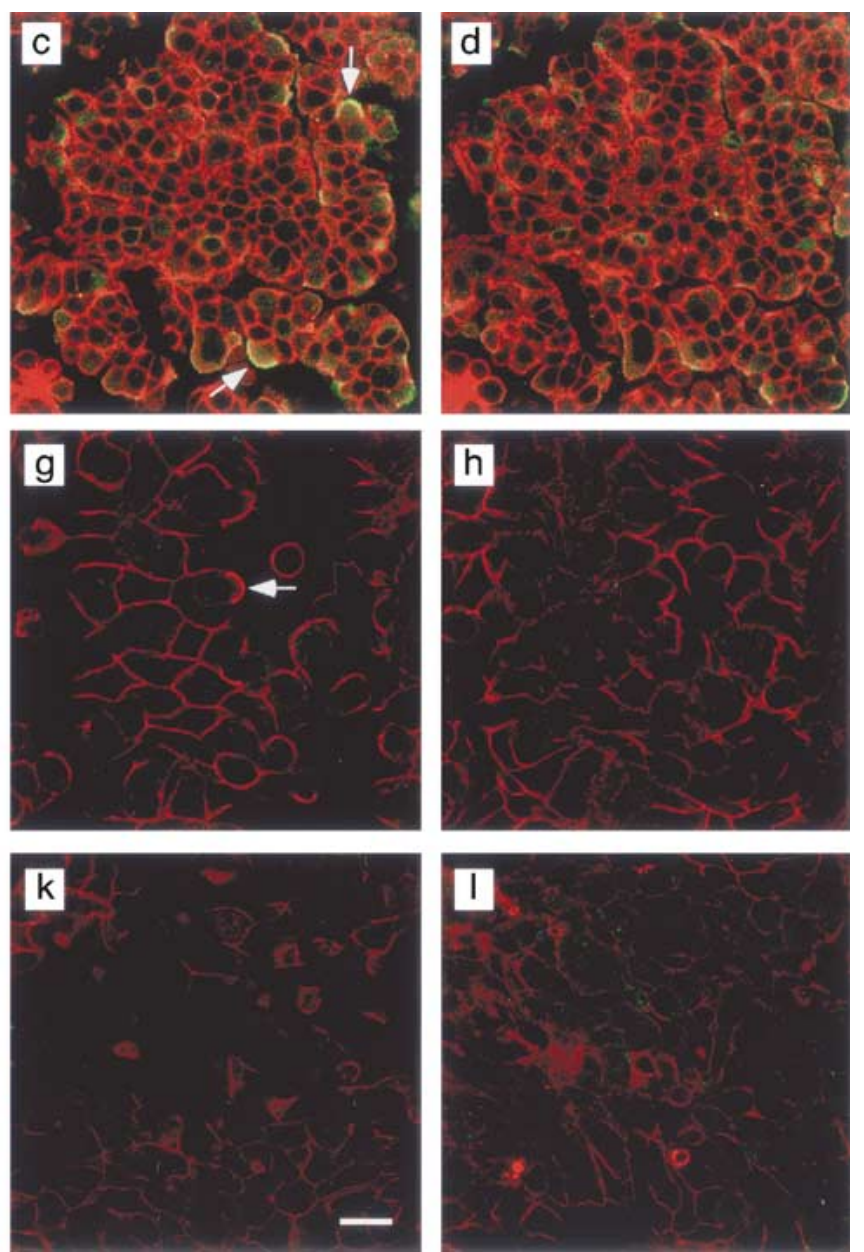

in wild-type (a-c) but not in Pds-knockout (e-g) mice. Panels $\mathbf{d}$ and $\mathbf{h}$ show the outermost sections of the same epithelium, where pendrin is absent in Pds-knockout mice. The apical membranes of only a few cells facing the lumen at this level of optical section are stained with the pendrin antibody (the proximal portion of the ES is very rough, with many grooves and invaginations). $\mathbf{i}-\mathbf{I}$. Optical sections through the epithelium of the distal portion of the endolymphatic sac of wild-type (i, j) and $P d s$-knockout $(\mathbf{k}, \mathbf{I})$ mice. Note that pendrin staining is seen in a subpopulation of cells of the wild-type but not Pds-knockout mice. The thickness of all optical sections was $0.4 \mu \mathrm{m}$. Scale bars $=20 \mu \mathrm{m}$.

endolymphatic hydrops) seen in the inner ears of $P d s^{-/-}$mice (Everett et al. 2001).

\section{Histological examination of the stria vascularis in $\mathrm{Pds}^{-{ }_{-}^{-}}$mice}

The severe endolymphatic hydrops encountered in the adult cochlea of $P d s^{-/-}$mice appears to be associated with a severely degenerated organ of Corti structure (Fig. 5a), consistent with previous findings (Everett et al. 2001). Importantly, the tunnel of Corti is well formed (Fig. 5a, inset), suggesting that slowed postnatal development of the cochlea is not a contributing cause of the lack of an EP in these animals (see below) (Marcus et al. 2002). However, striking 

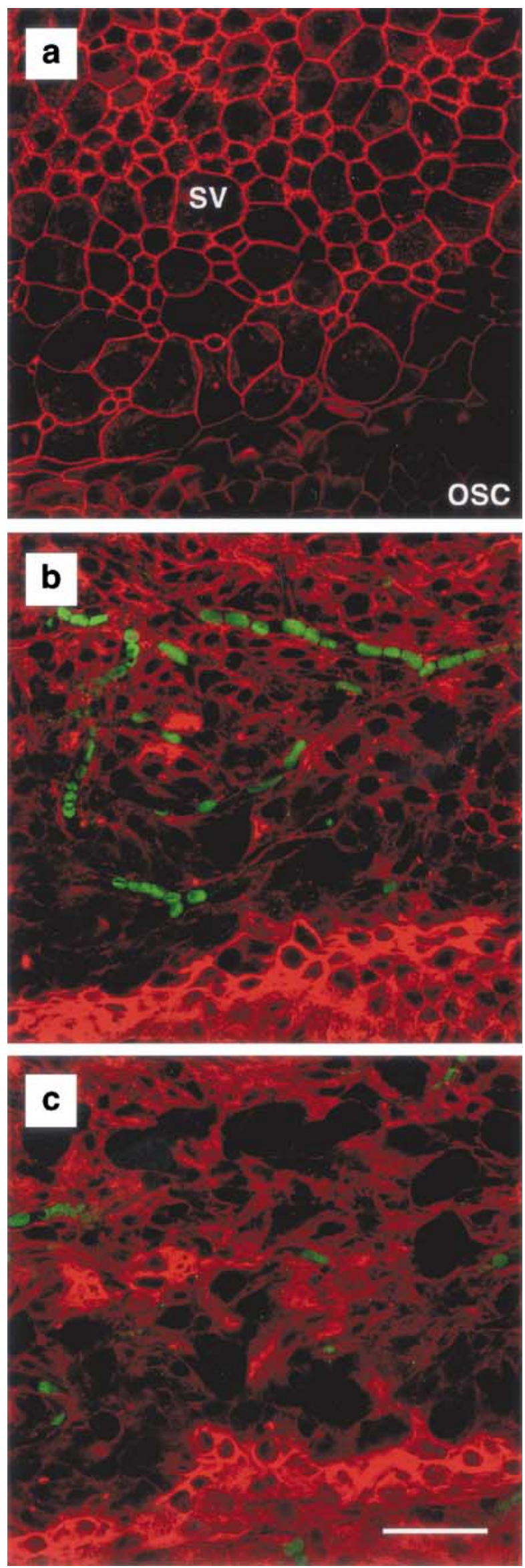

FIG. 4. Examination of the lateral wall of the cochlea in Pdsknockout mice by scanning confocal microscopy. Whole-mount cochlea preparations from an adult Pds-knockout mouse were stained with an anti-pendrin antibody followed by FITC-conjugated anti-rabbit antiserum and rhodamine-phalloidin. a-c. Optical sections through the epithelium of the stria vascularis and spiral prominence region (SV: stria vascularis; OSC: outer sulcus cells). a. No pendrin immunoreactivity (green; compare with Fig. 1a) was detected in the spiral prominence region (SV: stria vascularis; OSC: outer sulcus cells). Marginal cells of the stria vascularis in Pdsknockout mice are irregular in shape and size (as opposed to the normal cobblestone arrangement; compare with Fig. 1a). b, c. Optical section through the intermediate cell layer, which is the only stria layer that is highly vascularized [note the nonspecific staining of erythrocytes (green) in the blood vessels of the stria vascularis], and then the basal cell layer. The presence of round and oval-shaped openings suggest degeneration of this cell layer and disruption of its barrier function. Optical sections were taken at depths of $4.5 \mu \mathrm{m}$ for b (intermediate cell layer) and $9.0 \mu \mathrm{m}$ for $\mathbf{c}$ (basal cell layer). Scale bar $=40 \mu \mathrm{m}$.

changes were seen in the lateral wall of the cochlea, including a dramatic reduction in the spiral ligament and a significant thinning of the stria vascularis (Fig. 5b). Specifically, the stria was $20.5 \pm 1.1 \mu \mathrm{m}$ thick in wild-type mice $(n=3)$, compared with $13.4 \pm 0.2 \mu \mathrm{m}$ thick in $P d s^{-/-}$mice $(n=4)$ (Fig. 5c).

\section{Measurement of endolymphatic potential and potassium levels}

In wild-type mice, penetration of the endolymphatic space with double-barreled electrodes resulted in abrupt voltage change at both electrodes, with the recordings returning to baseline upon withdrawal (Fig. 6a). The EP and $\left[\mathrm{K}^{+}\right]$in the cochlear endolymph of wild-type mice [basal turn: $96.2 \pm 3.9 \mathrm{mV}$, $113.0 \pm 10.9 \mathrm{mM}(n=6)$; apical turn: $92.3 \pm 2.6 \mathrm{mV}$, $120.0 \pm 7.8 \mathrm{mM}(n=6)$; Fig. $6 \mathrm{~b}]$ were similar to values reported previously (Marcus et al. 2002; Sadanaga and Morimitsu 1995; Yamasaki et al. 2000). In $\mathrm{Pds} \mathrm{s}^{-1-}$ mice, the EP was dramatically reduced in both the basal $[-15.0 \pm 5.0 \mathrm{mV}(n=5)]$ and apical $[-2.5 \pm 0$. $9 \mathrm{mV}(n=5)]$ turns. In contrast, the $\left[\mathrm{K}^{+}\right]$was normal in $P d s^{-/-}$mice [basal turn: $104.1 \pm 21.7 \mathrm{mM}(n=5)$; apical turn: $101.1 \pm 12.4 \mathrm{mM}(n=5)$; Fig. $6 \mathrm{~b}]$. In wild-type mice, anoxia reduced the strongly positive $\mathrm{EP}$ in the apical cochlear turn to $-37.3 \pm 1.4 \mathrm{mV}$ $(n=3)$ within 3-5 min (Fig. 6c); in contrast, anoxia reduced the EP in the apical cochlear turn of $\mathrm{Pds} \mathrm{s}^{-/-}$ mice by less than $4 \mathrm{mV}$ to $-3.1 \pm 0.3 \mathrm{mV}$ ( $n=2$; Fig. 6c). Interestingly, $P d s^{-/-}$mice were found to be normal with respect to utricular potential (UP) and utricular $\left[\mathrm{K}^{+}\right]$; specifically, the UP was near zero (wild-type: $-1.0 \pm 3.8 \mathrm{mV}, \quad n=6 ; \quad P d s^{-/-}$mice: $0.0 \pm 3.3 \mathrm{mV}, n=4)$ and utricular $\left[\mathrm{K}^{+}\right]$was normal (wild-type: $107.6 \pm 8.8 \mathrm{mM}, \quad n=6 ; P d s^{-/-}$mice: $109.3 \pm 18.4 \mathrm{mM}, n=4)$ in both wild-type and $P d s^{-/-}$ mice (Fig. 6d). 

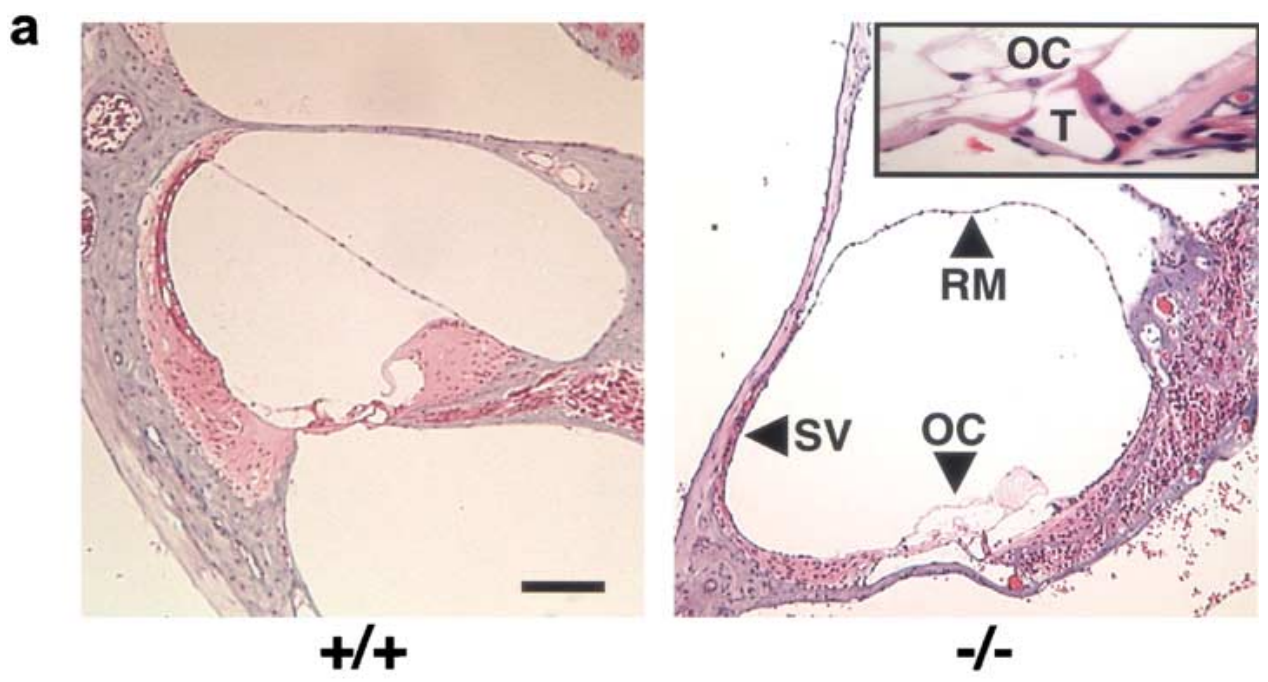

b

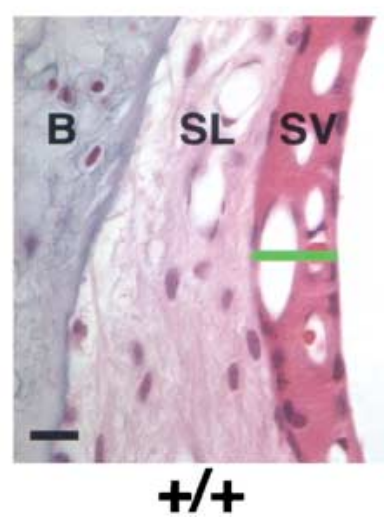

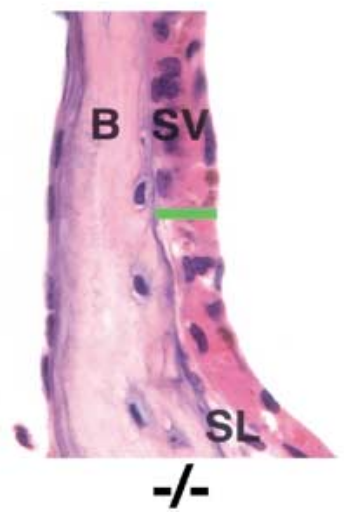

\section{DISCUSSION}

Studies of Pendred syndrome patients (Everett et al. 1997) and Pds-knockout mice (Everett et al. 2001) convincingly demonstrate that pendrin is essential for the normal functioning of the mammalian inner ear. In both humans and mice, the absence of pendrin results in deafness and, in most instances, vestibular dysfunction. In the present study, we elucidated the expression pattern of pendrin in the mouse inner ear and performed direct physiological measurements of inner-ear fluids produced in the presence and absence of pendrin. The latter provided insight about the role of pendrin in the formation of a positive EP and a high $\left[\mathrm{K}^{+}\right]$in cochlear endolymph, both of which are known to be essential for normal auditory function.

Pendrin is expressed in the lateral wall of the cochlea, more precisely in the cells of the spiral prominence as well as the outer sulcus cells and their associated processes [i.e., the outer sulcus cell roots (Duvall 1969; Galic and Giebel 1989)]. These immunolocalization results are in agreement with data generated previously by mRNA in situ hybridization (Everett et al. 1999). The outer sulcus cells are situ-
FIG. 5. Comparison of cochlear structure in wild-type and Pdsknockout mice, a. Microscopic examination of the basal turn of the cochlear duct in wild-type $(+/+)$ and $P d s$-knockout (-/-) adult mice ( $\sim 6$ weeks old). Scale bar $=0.1 \mathrm{~mm}$, applies to both $\mathbf{a}$ and $\mathbf{b}$. The small size of scala tympani is a typical finding in $P d s$-knockout mice. A highermagnification view of the organ of Corti from a Pds-knockout mouse showing open tunnel space $(T)$ is also provided (inset of the right panel). b. Microscopic examination of the lateral wall of the cochlear duct (basal turn) in wild-type and $P d s$-knockout mice. Scale bar $=10 \mu \mathrm{m}$. c. Bar graph depicting the maximal thickness of the stria vascularis in wild-type $(n=3)$ and Pds-knockout $(n=4)$ mice. The green bars in $\mathbf{b}$ illustrate the positions of these measurements in those specimens. RM, Reissner's membrane; SV, stria vascularis; $\mathrm{OC}$, organ of Corti; $\mathrm{T}$, tunnel of Corti; B, bone; SL, spiral ligament. Significance between groups was tested with the $t$-test for unpaired samples; ${ }^{*}, P<0.05$.

ated in the lateral wall of the cochlear duct, between the spiral prominence cells adjacent to the stria vascularis and Claudius cells. Capillaries run between the outer sulcus cells and their roots, and it is thought that these cells transport endolymph electrolytes from the cochlear duct to the capillaries (Hawkins 1976). Outer sulcus cells serve to mediate the regulation of sodium and potassium levels in endolymph (Chiba and Marcus 2000, 2001; Marcus and Chiba 1999), although many details of how this is accomplished remain to be determined. The expression of a known anion transporter, pendrin, in outer sulcus cells is thus consistent with the proposed role of this protein in maintaining the ionic composition of endolymph (Everett et al. 1999, 2001). Moreover, the dramatic changes in surface development of the outer sulcus cells in mouse occur between postnatal days 6 and 14, when cuboidal cells covering the outer sulcus cells degenerate to expose a newly forming cell layer (Lim and Anniko 1985). In Pds-knockout mice, the massive degeneration of outer hair cells is seen mostly after postnatal day 14 (Everett et al. 2001), corresponding to the period of functional maturation of the outer sulcus cells. 
a
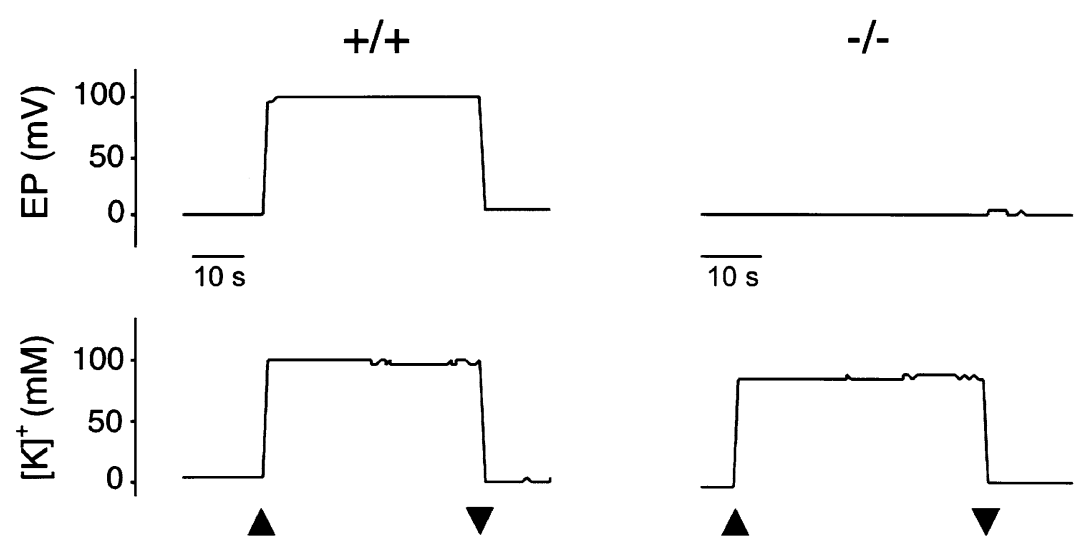

b

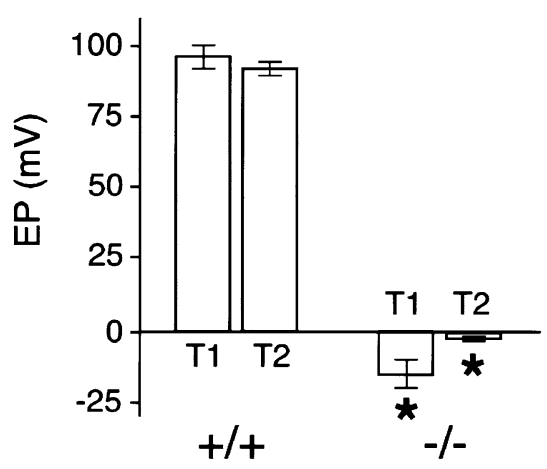

$$
+/+-/-
$$

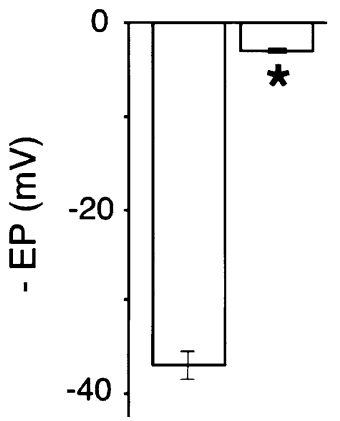

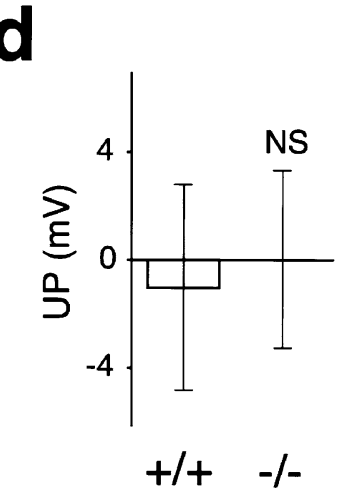

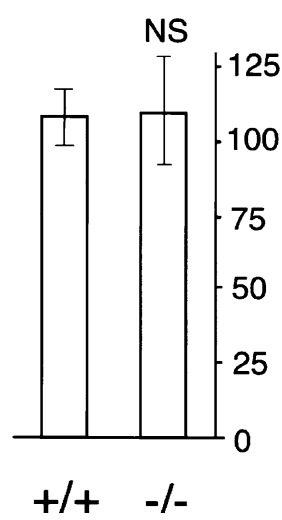

FIG. 6. Endolymphatic potential (EP) and $\left[\mathrm{K}^{+}\right]$in the cochlea and utricle of wild-type and $P d s$-knockout mice. Inner-ear specimens from wild-type $(+/+)$ and $P d s$-knockout (-/-) mice were subjected to various electrophysiological studies. a. Representative measurements of EP and $\left[\mathrm{K}^{+}\right]$from the apical cochlear turn. Arrow up, electrode insertion into scala media. Arrow down, extraction of electrode, $\mathbf{b}$. Summary of EP and $\left[\mathrm{K}^{+}\right]$in the basal (T1) and apical (T2) turns of the cochlea, $\mathbf{c}$. Steady-state EP from the apical turn of the cochlea during anoxia (-EP). d. Utricular potential (UP) and endolymphatic $\left[\mathrm{K}^{+}\right]$in the utricle. Significance between groups was tested with the $t$-test for unpaired samples; *, $P<0.05$; NS, not significant.
Endolymph in the cochlea is a unique and vitally important extracellular fluid. Its ionic composition is similar to that of an intracellular microenvironment, which is high in potassium and low in sodium (Wangemann and Schacht 1996). The maintenance of such an ionic balance in endolymph and the establishment of a positive EP are essential for normal auditory function. Potassium serves as the currentcarrying ion through the transduction channels of the sensory hair cells, and the EP serves as part of the requisite driving force. Potassium is secreted by the strial marginal cells, and the EP is generated across the intermediate cells, which form a functional syncytium with the basal cell barrier (Marcus et al. 2002). Thus, one can readily appreciate how major perturbations in the ionic milieu of endolymph can have adverse consequences for inner-ear structure and function. Indeed, the results reported here, coupled with previous studies of $P d s$-knockout mice (Everett et al. 2001), reveal the range of inner-ear abnormalities encountered in the absence of pendrin: endolymphatic hydrops, absence of an EP, and thinning of both the stria vascularis and the spiral ligament. The hydrops is likely due, at least in part, to 
disruption of the cation-absorbing function of the outer sulcus cells and vestibular transitional cells (see below), both known to be responsible for absorbing sodium and potassium from cochlear endolymph (Lee et al. 2001; Marcus and Chiba 1999) and both sites of pendrin expression. While pendrin has been shown to be an anion transporter (Scott et al. 1999), its function in the inner ear appears to be required for proper transepithelial absorption of cations. However, the nature of any proposed interactions between pendrin and known inner-ear cation transporters (Chiba and Marcus 2001) is currently not known.

In $P d s$-knockout mice, the delayed morphologic changes in the $\mathrm{K}^{+}$-secreting marginal cells of the stria vascularis and the physical separation of these cells from those normally expressing pendrin cannot yet be explained. However, the changes are likely brought about either by disruption of a paracrine signaling pathway between outer sulcus cells and strial marginal cells or changes in other important constituents of the inner-ear fluids (e.g., calcium and $\mathrm{pH})$. Similar issues are relevant for the degeneration of hair cells seen in mice lacking $\mathrm{KCNJ} 10 \mathrm{~K}^{+}$channels in strial intermediate cells (Marcus et al. 2002). The normal endolymph $\left[\mathrm{K}^{+}\right]$in $P d s$-knockout mice suggests that the morphologic changes do not interfere with fundamental secretory mechanisms of the marginal cells. However, even though the basic mechanisms seem to be intact, the $\mathrm{K}^{+}$secretory rate could conceivably be reduced if there is decreased cation absorption by outer sulcus cells.

The findings reported here have other interesting implications. First, the thinner stria vascularis in $P d s$ knockout mice may be due to increased endolymph pressure and dilation of the scala media compartment or consequent degeneration of basal and/or intermediate cells (Figs. 4 and 5). In viable dominant spotting mice $\left(W^{*} / W^{\nu}\right)$, which lack intermediate cells, the stria is reduced in thickness by about the same amount seen in Pds-knockout mice, and the absence of intermediate cells is correlated with the absence of an EP (Carlisle et al. 1990). Indeed, recent studies have demonstrated that the KCNJ10 potassium channels expressed in intermediate cells are responsible for generating the EP (Marcus et al. 2002). Second, the thinner spiral ligament is a potentially important observation in light of the hypothesis that fibrocytes in this connective tissue serve to transport potassium from the organ of Corti to the stria vascularis via a gap junction system (Kikuchi et al. 1995). A similar gap junction system has been identified in the vestibular system (Kikuchi et al. 1994). If the apparent degeneration of the spiral ligament reduces the functionality of its constituent fibrocytes, the importance of these cells in potassium homeostasis could be called into question since the $\left[\mathrm{K}^{+}\right]$of cochlear endolymph in pendrin-deficient mice was found to be normal. On the other hand, the efflux of potassium from endolymph may be reduced in $P d s$-knockout mice since the driving force (i.e., the EP) is reduced and the hair cell efflux pathway is compromised or absent.

The EP changes in Pds-knockout mice observed under anoxic conditions indicate a loss of functional hair cells within the organ of Corti. In a normal mouse, anoxia (or transport inhibitors) interferes with active transport in the stria vascularis and causes the normal $\mathrm{EP}$ of about +80 to $100 \mathrm{mV}$ to decline within minutes to about $-30 \mathrm{mV}$. This negative value reflects the activity of viable hair cells (see equation 7 with $E_{T}=0$ in Dallos 1983), which maintain function during anoxia for at least $30 \mathrm{~min}$ by glycolysis (Thalmann et al. 1972). The reduced magnitude of the negative EP value measured in pendrin-deficient mice is consistent with a loss of functional hair cells, with the difference in EP seen between the apical and basal turns in these animals perhaps reflecting a variable extent of hair cell loss. A similar reduction in -EP was observed in mice lacking the potassium channel KCNJ10 within the strial intermediate cells; these mice show degeneration in the organ of Corti (unpublished observations; Marcus et al. 2002).

There are limits to extrapolating data from wholeanimal gene-knockout studies for explaining fully the corresponding human condition. For example, one difference between humans and mice is the time of EP establishment, which does not occur until the second and third week after birth in rodents. To address this issue, we included the analysis of a valid indicator of cochlear development, the tunnel of Corti, and the measurement of the EP and $\left[\mathrm{K}^{+}\right]$in the vestibular system. As with KCNJ10-knockout mice (Marcus et al. 2002), $P d s$-knockout mice have a welldeveloped tunnel space in the organ of Corti, consistent with generally normal cochlear development. This finding, along with the normal vestibular endolymphatic $\left[\mathrm{K}^{+}\right]$, supports our interpretation that the absence of an EP is due specifically to local alterations of the stria vascularis. The lack of changes in the utricular potential (UP) is consistent with the hypothesis that the abnormalities caused by the absence of pendrin occur within the deep layers of the stria vascularis, for which there is no counterpart in the vestibular system.

In fact, a slightly different (perhaps more complex) situation might be occurring within the vestibular end-organ, where pendrin is expressed in the transitional cells that reside next to the sensory epithelium. These cells occupy a position in the vestibular labyrinth analogous to that of the outer sulcus cells in the cochlea, situated between the potassium- 
secreting cells and the sensory hair cells. In the utricle and saccule, transitional cells may play a role in the formation and/or remodeling of otoconia (Ciges et al. 1983), which is a $\mathrm{pH}$-dependent process. Interestingly, otoconia in Pds-knockout mice are notably absent or, in some cases, grossly abnormal (Everett et al. 2001). Thus, the role of pendrin in the vestibular end-organ might include maintaining the appropriate endolymphatic $\mathrm{pH}$, perhaps through the transport of bicarbonate, and its absence may lead to an abnormal local $\mathrm{pH}$ and the formation of aberrant otoconia. It is relevant to point out that pendrin is present in the intercalated cells of the cortical collecting duct of the kidney, where it plays a role in bicarbonate transport (Royaux et al. 2001).

Finally, pendrin is also expressed in the apical membrane of a subpopulation of cells of the endolymphatic sac. The morphology of these cells coupled with the presence of oxidative enzymes and cytokeratin-7, which is characteristic of secretory cells, suggests that they might be involved in energy-dependent electrolyte and water transport (Danckwardt-Lilliestrom et al. 2000). The endolymph of the cochlea and vestibular end-organ is potassium-rich and sodiumpoor, whereas the luminal content of the endolymphatic sac is sodium-rich and potassium-poor (Morgenstern 1985; Silverstein and Schuknecht 1966). The latter fluid has a $\mathrm{pH}$ of 6.65 in the guinea pig (Tsujikawa et al. 1992). Perhaps the function of pendrin in the endolymphatic sac is to maintain the ionic and/or $\mathrm{pH}$ homeostasis between these two compositionally distinct fluids. It is interesting to note that there are ultrastructural similarities between the epithelia of the renal collecting duct [where pendrin is involved in bicarbonate transport (Royaux et al. 2001)] and the inner-ear endolymphatic sac (Dahlmann and von During 1995; Peters et al. 2002).

In summary, our studies demonstrate that pendrin is expressed in a restricted subset of cells in the inner ear, all of which are in contact with endolymph and are believed to play a role in regulating the unusual ionic composition of this fluid. The presence of pendrin in these cells is essential for auditory and vestibular function, as evidenced by the phenotypic features of humans and mice devoid of normal pendrin. Structurally, the cochlea of $P d s$-knockout mice is associated with morphological abnormalities of spiral ligament and stria vascularis cells and with degeneration of sensory hair cells, even though none of these cell types express pendrin. Physiologically, the lack of pendrin in these mice results in the absence of a normal EP. These observations suggest that pendrin function is needed for normal development of inner-ear structures. Together, these studies greatly advance our understanding of pendrin function in the inner ear, provide important insight into the eti- ology of deafness in Pendred syndrome, and point to a series of future studies that might provide additional details about the anion(s) being transported by pendrin in these different cells of the inner ear.

\section{ACKNOWLEDGMENTS}

This work was supported in part by NIH grant R01-DC00212 (to D.C.M.).

\section{REFERENCES}

Belyantseva iA, Adler HJ, Curi R, Frolenkov Gi, Kachar B. Expression and localization of prestin and the sugar transporter GLUT-5 during development of electromotility in cochlear outer hair cells. J. Neurosci. 20:RC116, 2000.

Bidart JM, Lacroix L, Evain-Brion D, Caillou B, Lazar V, Frydman D, Bellet D, Filetti S, Schlumberger M. Expression of Na+/Isymporter and Pendred syndrome genes in trophoblast cells. J. Clin. Endocrinol. Metab. 85:4367-4372, 2000a.

Bidart JM, Mian C, Lazar V, Russo D, Filetti S, Caillou B, Schlumberger M. Expression of pendrin and the Pendred syndrome (PDS) gene in human thyroid tissues. J. Clin. Endocrinol. Metab. 85:2028-2033, 2000b.

Carlisle L, Steel K, Forge A. Endocochlear potential generation is associated with intercellular communication in the stria vascularis: structural analysis in the viable dominant spotting mouse mutant. Cell Tissue Res. 262:329-337, 1990.

Chiba T, Marcus DC. Nonselective cation and BK channels in apical membrane of outer sulcus epithelial cells. J. Membr. Biol. 174:167-179, 2000.

Chiba T, Marcus DC. Basolateral K+ conductance establishes driving force for cation absorption by outer sulcus epithelial cells. J. Membr. Biol. 184:101-112, 2001.

Ciges M, Campos A, Revelles F. The origin of the otoconia in the rat. Acta Otolaryngol. 95:522-527, 1983.

Dahlmann A, von During M. The endolymphatic duct and sac of the rat: a histological, ultrastructural, and immunocytochemical investigation. Cell Tissue Res. 282:277-289, 1995.

Dallos P. Some electrical circuit properties of the organ of Corti. I. Analysis without reactive elements. Hear. Res. 12:89-119, 1983.

Danckwardt-Lilliestrom N, Friberg U, Kinnefors A, Rask-AnderSEN H. Ultrastructural analysis of 20 intraosseous endolymphatic sacs from patients with cerebello-pontine angle tumours. A surgically obtained control material for histopathological studies. Auris Nasus Larynx 27:311-321, 2000.

DAS VK. Pendred's syndrome with episodic vertigo, tinnitus and vomiting and normal bithermal caloric responses. J. Laryngol. Otol. 101:721-722, 1987.

Duvall AJ 3RD. The ultrastructure of the external sulcus in the guinea pig cochlear duct. Laryngoscope 79:1-29, 1969.

Everett La, Glaser B, Beck JC, Idol JR, Buchs A, Heyman M, Adawi E, Hazani E, Nassir E, Baxevanis AD, Sheffield VC, Green ED. Pendred syndrome is caused by mutations in a putative sulphate transporter gene (PDS). Nat. Genet. 17:411-422, 1997.

Everett LA, Morsli H, Wu DK, Green ED. Expression pattern of the mouse ortholog of the Pendred's syndrome gene (Pds) suggests a key role for pendrin in the inner ear. Proc. Natl. Acad. Sci. USA 96:9727-9732, 1999.

Everett LA, Belyantseva IA, Noben-Trauth K, Cantos R, Chen A, Thakkar Si, Hoogstraten-Miller SL, Kachar B, Wu DK, Green ED. Targeted disruption of mouse Pds provides insight about 
the inner-ear defects encountered in Pendred syndrome. Hum. Mol. Genet. 10:153-161, 2001.

Fraser GR, Morgans ME, Trotter WR. The syndrome of sporadic goiter and congenital deafness. Quart. J. Med. 29:279-295, 1960.

Furuta H, Mori N, Fujita M, Saka S. Ultrastructure of the endolymphatic sac in the mouse. Acta Anat. (Basel) 14:193-198, 1991.

Galic M, Giebel W. An electron microscopic study of the function of the root cells in the external spiral sulcus of the cochlea. Acta Otolaryngol. Suppl. 461:1-15, 1989.

HawkINS JR JE. Microcirculation in the labyrinth. Arch. Otorhinolaryngol. 212:241-251, 1976.

Hultcrantz M, Bagger-Sjoback D, Rask-Andersen H. The pre- and postnatal maturation of the epithelium in the endolymphatic sac. An electron microscopic survey. Acta Otolaryngol. 105:303311, 1988.

Johnsen T, Jorgensen MB, Johnsen S. Mondini cochlea in Pendred's syndrome. A histological study. Acta Otolaryngol. 102:239-247, 1986.

Kikuchi T, Adams JC, Paul DL, Kimura RS. Gap junction systems in the rat vestibular labyrinth: immunohistochemical and ultrastructural analysis. Acta Otolaryngol. 114:520-528, 1994.

Kikuchi T, Kimura RS, Paul DL, Adams JC. Gap junctions in the rat cochlea: immunohistochemical and ultrastructural analysis. Anat. Embryol. (Berl.) 191:101-118, 1995.

Lacroix L, Mian C, Caillou B, Talbot M, Filetti S, Schlumberger JM, Bidart JM. Na(+)/I(-) symporter and Pendred syndrome gene and protein expressions in human extra-thyroidal tissues. Eur. J. Endocrinol. 144:297-302, 2001.

LeE JH, Chiba T, Marcus DC. P2X2 receptor mediates stimulation of parasensory cation absorption by cochlear outer sulcus cells and vestibular transitional cells. J. Neurosci. 21:9168-9174, 2001.

Lim DJ, AnNiko M. Developmental morphology of the mouse inner ear. A scanning electron microscopic observation. Acta Otolaryngol. Suppl. 422:1-69, 1985.

LuNDQUIST PG. Aspects on endolymphatic sac morphology and function. Arch. Otorhinolaryngol. 212:231-240, 1976.

Marcus DC, Chiba T. K+ and Na+ absorption by outer sulcus epithelial cells. Hear. Res. 134:48-56, 1999.

Marcus DC, Wu T, Wangemann P, Kofuji P. KCNJ10 (Kir4.1) potassium channel knockout abolishes endocochlear potential. Am. J. Physiol. Cell Physiol. 282:C403-C407, 2002.

Morgenstern C. Pathophysiology, clinical aspects and conservative therapy of Meniere disease. Arch. Otorhinolaryngol. Suppl. 1:166, 1985.

Peters ta, Tonnaer EL, Kujjers W, Cremers CW, Curfs JH. Differences in endolymphatic sac mitochondria-rich cells indicate specific functions. Laryngoscope 112:534-541, 2002.
Phelps PD, Coffey RA, Trembath RC, Luxon lM, Grossman AB, Britton Ke, Kendall-Taylor P, Graham JM, Cadge BC, Stephens SG, Pembrey ME, Reardon W. Radiological malformations of the ear in Pendred syndrome. Clin. Radiol. 53:268273, 1998.

Reardon W, Trembath RC. Pendred syndrome. J. Med. Genet. 33:1037-1040, 1996.

Rillema JA, Hill MA. Prolactin regulation of the pendrin-iodide transporter in the mammary gland. Am. J. Physiol. Endocrinol. Metab. 284:E25-E28, 2003.

Royaux IE, Suzuki K, Mori A, Katoh R, Everett LA, Kohn LD, GREEN ED. Pendrin, the protein encoded by the Pendred syndrome gene (PDS), is an apical porter of iodide in the thyroid and is regulated by thyroglobulin in FRTL- 5 cells. Endocrinology 141:839-845, 2000.

Royaux IE, Wall SM, Karniski LP, Everett LA, SuZuki K, Knepper ED, Green ED. Pendrin, encoded by the Pendred syndrome gene, resides in the apical region of renal intercalated cells and mediates bicarbonate secretion. Proc. Natl. Acad. Sci. USA 98:4221-4226, 2001.

Sadanaga M, Morimitsu T. Development of endocochlear potential and its negative component in mouse cochlea. Hear. Res. 89:155-161, 1995.

Scott DA, Wang R, Kreman TM, Sheffield VC, Karniski LP. The Pendred syndrome gene encodes a chloride-iodide transport protein. Nat. Genet. 21:440-443, 1999.

Silverstein H, Schuknecht HF. Biochemical studies of inner ear fluid in man. Changes in otosclerosis, Meniere's disease, and acoustic neuroma. Arch. Otolaryngol. 84:395-402, 1966.

Stinckens C, Huygen PL, Joosten FB, Van Camp G, Otten B, CreErs CW. Fluctuant, progressive hearing loss associated with Meniere like vertigo in three patients with the Pendred syndrome. Int. J. Pediatr. Otorhinolaryngol. 61:207-215, 2001.

Suzuki K, Royaux IE, Everett LA, Mori-Aoki A, Suzuki S, Nakamura K, Sakai T, Katoh R, Toda S, Green ED, Kohn LD. Expression of PDS/Pds, the Pendred syndrome gene, in endometrium. J. Clin. Endocrinol. Metab. 87:938, 2002.

Thalmann R, Mryoshi T, Thalmann I. The influence of ischemia upon the energy reserves of inner ear tissues. Laryngoscope 82:2249-2272, 1972.

Tsujikawa S, Yamashita T, Amano H, Kumazawa T, Vosteen KH. Acidity in the endolymphatic sac fluid of guinea pigs. ORL J. Otorhinolaryngol. Relat. Spec. 54:198-200, 1992.

Wangemann P, Schacht J. Homeostatic mechanisms in the cochlea. In: Dallos P, Popper AN, Fay RR (eds) The Cochlea. SpringerVerlag, New York, pp 130-185, 1996.

Yamasaki M, Komune S, Shimozono M, Matsuda K, Haruta A. Development of monovalent ions in the endolymph in mouse cochlea. ORL J. Otorhinolaryngol. Relat. Spec. 62:241-246, 2000 . 